\title{
Atkins - the superior slimming diet?
}

Abstract

Four diets of varying composition, from the high-protein Atkins diet to the balanced educational tool LEARN, showed modest one-year weight-loss results but had no adverse effects. None of the four diets reaches the standard figure of at least $5-10 \%$ used to evaluate the success of weight loss treatments. It seems reasonable to state that a well-conducted study has shown us that modest weight loss can be achieved in various ways. However, this is no breakthrough demonstrating that one method is superior to any other, and no reason to argue that those in favour of high-protein diets were the first to discover the truth of weight loss programs.

$\mathrm{F}$ rom a scientific point of view it is clearly surprising that diets have repeatedly been promoted without any proper scientific ground. The Atkins diet was a huge commercial success. But the proper scientific evaluation, which obviously should have been performed by the inventor of the diet, was not performed until decades later-and by other scientists. One study demonstrated that after six months of treatment of moderately obese but otherwise healthy individuals weight loss with the Atkins diet was slightly higher than in a matched control sample. However, in a parallel study, results after 12 months of treatment showed no difference.

The ongoing interest in different popular diets has now led serious scientists to conduct properly designed prospective randomised and controlled trials, which of course should have been performed before any claims were made whatsoever. Gardner et al. recently published such a well-designed study, the A TO Z Weight Loss Study, which was performed on 311 free-living overweight and obese non-diabetic pre-menopausal women - exactly the kind of individuals who would particularly look for such treatment programs. Weight loss after one year was a primary outcome and secondary outcomes included the standard metabolic risk factors (1). The decrease in reported mean energy intake did not differ between the four groups. Compliance was surprisingly high with between 76 and $88 \%$ participation at the 12 months final follow-up. After 12 months the weight loss with Atkins was $4.7 \mathrm{~kg}$, with the Zone diet $1.6 \mathrm{~kg}$, with LEARN $2.6 \mathrm{~kg}$ and with the Ornish diet $2.2 \mathrm{~kg}$. There was a statistically different weight loss between the Atkins and the Zone diet but not between the other alternatives. The metabolic risk factors improved, in principle in relation to weight loss.
The publication, in one of the most respected international journals, caused intensive medial activity. Journalists published articles demonstrating that the final word had been said, and clinicians who had been advocating the high-protein diet on personal grounds felt that the article had eventually brought justice to their case. There seem to be few reasons to argue that a high-protein diet has adverse effects - a hypothesis that has been repeatedly forwarded and with particular concern for subjects with potential renal disease. However, although the trial is well conducted it is important not to overstate the outcome and the authors are careful in their interpretation of the data.

A main shortcoming is that the mean initial body weight was around $100 \mathrm{~kg}$, which means that the 12 months weight loss even in the Atkins diet was just about $5 \%$. A standard figure to evaluate success of any treatment is a weight loss of at least $5-10 \%$. But the authors point out another limiting aspect: For some women weight loss was still continuing, and it might have been unfair to close the study after 12 months, when in fact for some individuals further weight loss could be anticipated.

Stephan Rössner

M73, Karolinska University Hospital Huddinge SE-141 86 Stockholm, Sweden E-mail: Stephan.Rössner@ki.se

\section{Reference}

1. Gardner CD, Kiazand A, Alhassan S, Kim S, Stafford RS, Balise RR, et al. Comparison of the Atkins, Zone, Ornish, and LEARN diets for change in weight and related risk factors among overweight premenopausal women. JAMA 2007; 297: 969-77. 